\title{
Relation of Systemic Arterial Pulse Pressure to Coronary Atherosclerosis in Patients With Mitral Stenosis
}

\author{
Tsung-Ming Lee, MD, Yueh-Juh Lin, MD, Sheng-Fang Su, PhD, Kuo-Liong Chien, MD, \\ Ming-Fong Chen, MD, Chiau-Suong Liau, MD, and Yuan-Teh Lee, MD
}

The relation of a wide systemic arterial pulse pressure to coronary atherosclerosis has not been fully defined. One hundred fifty-nine patients $>40$ years old with symptomatic mitral stenosis (MS) who received routine coronary angiography were classified into 2 groups according to the presence of $\geq 50 \%$ diameter narrowing of $\geq 1$ coronary artery ( $n=48$ ) or no significant disease ( $n=$ 111). Pulse pressure was determined both by noninvasive sphygmomanometer and invasive catheterization methods. There were no significant differences in risk factors of coronary artery disease (CAD) or the severity of MS between the 2 groups. From multivariate logistic regression analysis, independent predictors of develop- ment of CAD in MS were age (standardized coefficient $\beta$ $=1.3437, p=0.0025)$, gender $(\beta=0.0107, p=$ $0.0105)$, mean blood pressure $(\beta=1.1839, p=$ $0.0105)$, and pulse pressure $(\beta=1.3157, p=0.0008)$. A wide pulse pressure ( $\geq 60 \mathrm{~mm} \mathrm{Hg}$ ) correlated with the presence of angiographically significant CAD with a sensitivity and specificity of $88 \%$ and $77 \%$. The negative predictive value was $93 \%$. Pulse pressure assessed by sphygmomanometry provided important clinical information. A wide pulse pressure in patients with MS was associated with a high incidence of CAD. (C) 1997 by Excerpta Medica, Inc.

(Am J Cardiol 1997;80:1035-1039)
A lthough several investigators have become actively involved in the study of risk factors in patients with mitral stenosis (MS), emphasis is usually placed on symptoms associated with coronary artery disease (CAD). ${ }^{1,2}$ There was either no blood pressure analysis or only the level itself of systolic, diastolic, or mean blood pressure was taken into consideration. The fact that the pulsatile component of blood pressure can, per se, play a role in atherogenesis, ${ }^{3}$ independently of mean arterial pressure, has not been evaluated. This investigation tests the role of pulse pressures in coronary atherogenesis in patients with MS.

\section{METHODS}

Patients: Between July 1987 and July 1996, 283 patients with symptomatic MS underwent balloon mitral valvuloplasty at the National Taiwan University Hospital. Coronary angiography was routinely performed in 196 patients aged $>40$. Among the 196 patients, 37 patients who had more than mild aortic valvular stenosis or regurgitation by catheterization were excluded from this study. In hypertensive subjects $(n=38)$, therapy was discontinued at least 5 half-lives betore the study. The remaining $159 \mathrm{pa}-$ tients were divided into 2 groups on the basis of the sevcrity of coronary artery lesions. Group 1 consisted of 48 patients ( 34 men and 14 women, mean age $62 \pm$

From the College of Medicine, National Taiwan University, Depart ment of Internal Medicine, Cardiology Section, National Taiwan University Hospital, Taipei, Taiwan; and the College of Medicine, National Cheng Kung University, Tainan, Taiwan, Republic of Chino Manuscript received March 2, 1997; revised manuscript received and accepted June 17, 1997

Address for reprints: Yuan-Teh Lee, MD, Cardiology Section, Department of Internal Medicine, National Taiwan University Hospital, 7 Chung-Shan S. Road, Taipei, Taiwan.
8 years [range 48 to 81 ]) with coronary artery diameter stenosis $\geq 50 \%$ measured by catheterization study. Group 2 consisted of 111 patients (88 women and 23 men, mean age $53 \pm 5$ years [range 42 to 78 ]) without significant $\mathrm{CAD}(<50 \%)$ as measured by catheterization. Ten and 29 patients had normal sinus rhythm in groups 1 and 2, respectively. The other 120 patients had atrial fibrillation. The presenting symptoms were exertional dyspnea (45 in group 1, 98 in group 2), anginal pain (7 in group 1, 5 in group 2) and atypical chest pain (5 in group 1,7 in group 2). Detailed clinical data are listed in Table 1.

Assessment of clinical parameters for coronary artery disease: The following variables were analyzed to identify factors related to pathogenesis of CAD: systolic blood pressure, diastolic blood pressure, mean blood pressure, pulse pressure, fasting blood sugar, cigarette smoking, serum cholesterol, and serum triglycerides. These variables were measured before breakfast on the morning after admission for percutaneous balloon mitral valvuloplasty.

Measurement of clinical arterial pressure: After obtaining informed consent, the patients were investigated. After 30 minutes' rest in the supine position, systolic and diastolic pressures were measured according to the American Heart Association Recommendation $^{4}$ with a standard mercury sphygmomanometer by the auscultatory method. Korotkoff phase I and V were taken as systolic and diastolic pressures. Blood pressure was measured 3 times, and the mean of all 3 measurements was used. Mean arterial pressure was calculated as the diastolic pressure plus one third pulse pressure. Pulse pressure was the differences between systolic and diastolic pressures.

Echocardiographic assessment: Study patients underwent 2-dimensional echocardiography with Doppler color flow mapping 1 to 2 days before balloon 


\begin{tabular}{|c|c|c|}
\hline Parameters & $\begin{array}{l}\text { Group } 1 \\
(n=48)\end{array}$ & $\begin{array}{l}\text { Group } 2 \\
(n=111)\end{array}$ \\
\hline Age $(y r)$ & $62 \pm 8$ & $53 \pm 5^{*}$ \\
\hline Men/women & $34 / 14$ & $23 / 88$ \\
\hline Atrial fibrillation & $38(79 \%)$ & $82(74 \%)$ \\
\hline Heart rate (beats/min) & $82 \pm 20$ & $79 \pm 21$ \\
\hline $\begin{array}{l}\text { Systolic arterial pressure } \\
\qquad(\mathrm{mm} \mathrm{Hg})\end{array}$ & $145 \pm 14$ & $119 \pm 11 *$ \\
\hline $\begin{array}{l}\text { Diastolic arterial pressure } \\
\qquad(\mathrm{mm} \mathrm{Hg}\}\end{array}$ & $74 \pm 11$ & $70 \pm 13$ \\
\hline $\begin{array}{l}\text { Mean arterial pressure } \\
(\mathrm{mm} \mathrm{Hg})\end{array}$ & $97 \pm 11$ & $87 \pm 11^{*}$ \\
\hline $\begin{array}{l}\text { Pulse pressure }(\mathrm{mm} \mathrm{Hg} \text { ) } \\
\text { CAD risk factors }\end{array}$ & $71 \pm 11$ & $48 \pm 12 *$ \\
\hline Hypertension & $15(31 \%)$ & $23(20 \%)$ \\
\hline Diabetes mellitus & $6(13 \%)$ & $10(9 \%)$ \\
\hline Smoking & $20(42 \%)$ & $43(39 \%)$ \\
\hline Total cholesterol $\{\mathrm{mg} / \mathrm{dl}\}$ & $182 \pm 42$ & $182 \pm 34$ \\
\hline $\begin{array}{l}\text { Total triglycerides } \\
\qquad(\mathrm{mg} / \mathrm{dll})\end{array}$ & $142 \pm 54$ & $161+89$ \\
\hline . & 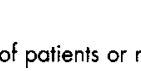 & \\
\hline
\end{tabular}

mitral valvuloplasty. A commercially available system (Hewlett-Packard Sonos 1000 or 1500, Andover, Massachusetts) was used. Left ventricular end-diastolic dimension (EDD), end-systolic dimension (ESD), interventricular septum thickness (IVS), posterior wall thickness (PW), and left ventricular ejection fraction were measured as suggested by the American Society of Echocardiography. ${ }^{5}$ Echocardiographic left ventricular mass was determined using the corrected formula proposed by Devereux ${ }^{6}$ :

Left ventricular mass $(\mathrm{g})=0.80$

$$
\times\left\{1.04 \times\left[(\mathrm{EDD}+\mathrm{IVS}+\mathrm{PW})^{3}-\mathrm{FDD}^{3}\right]\right\}+0.6
$$

Systolic wall stress was calculated by the method of Grossman et al: ${ }^{7}$

Wall stress $=($ systolic blood pressure $)$

$$
\times(\mathrm{ESD}) / 4 \cdot(\mathrm{PW})(1+\mathrm{PW} / \mathrm{ESD})
$$

Left ventricular mass was indexed by body surface area $\left(\mathrm{g} / \mathrm{m}^{2}\right)$. Mitral valve area was calculated by the Doppler pressure half-time ${ }^{8}$ and planimetry methods. In the planimetry method, the smallest orifice of the mitral valve was located in the parasternal short-axis view, and the valve area was planimetered at the maximal opening in diastole from a freeze-frame image. Measurements in patients with atrial fibrillation were averaged for 5 consecutive beats. Video images were recorded for off-line analysis.

Catheterization procedure: Before balloon valvuloplasty, diagnostic right and left heart catheterization and angiography were performed from a femoral approach as described previously. ${ }^{9}$ Cardiac output was determined by the thermodilution method in triplicate or quadruplicate by injecting $10 \mathrm{ml}$ of ice-cold saline solution. Coronary angiograms were recorded in patients aged $>40$ years. Cine angiograms were re- corded at 60 frames/s through a lens with a focal length of $135 \mathrm{~mm}$ and with an x-ray field of $15 \mathrm{~cm}$. Multiple pairs of perpendicular views $\left(90^{\circ}\right)$ of the left and right coronary arteries were obtained. For each lesion, the view showing the most severe degree of stenosis was used for analysis. Coronary angiograms were visually analyzed by consensus of 2 experienced cardiologists without knowledge of clinical information. Coronary lesions of the last 30 patients $(8 \mathrm{pa}$ tients in group 1,22 in group 2) were evaluated both by on-line digital coronary angiograms (DCI System, Philips, Inc., Best, The Netherlands) ${ }^{10}$ and by visual analysis. Ascending aortic blood pressure was measured and mean arterial pressure was calculated as diastolic pressure plus one third pulse pressure. Heart rate was determined from a continuous electrocardiographic tracing. Stroke index was calculated by dividing cardiac output by heart rate and body surface areas. Vascular resistance was calculated by dividing mean arterial pressure minus mean right atrium pressure by cardiac output.

Statistical analysis: Values are reported as mean \pm $1 \mathrm{SD}$. A chi-square test was used to compare categoric variables. The differences of 2 measurement methods (sphygmomanometer and catheterization) of pulse pressures were compared with paired Student's $t$ test. The other continuous variables between the 2 groups were compared with Student's $t$ test for 2-tailed unpaired observation. For identification of independent predictors of $\mathrm{CAD}$, a multivariate logistic regression analysis was used. Results were expressed as standardized coefficient $(\beta)$. Agreement between the 2 measurement methods (DCI and visual analysis) for rating the severity of coronary artery lesions in the last 30 patients was evaluated using $\kappa \cdot{ }^{11} \mathrm{~A} \kappa$ of 1 indicates perfect agreement; a $\kappa$ of 0 indicates only chance agreement between the 2 methods. In general, values $>0.75$ indicate excellent agreement, values of 0.4 to 0.75 indicate good agreement, and values $<0.4$ indicate marginal agreement. A p value $<0.05$ was considered statistically significant.

\section{RESULTS}

There was agreement between the 2 measurement methods on the severity of CAD in 28 of 30 coronary angiograms with the cutoff point of $50 \%$ coronary diameter stenosis. The overall $\kappa$ was 0.93 , indicating excellent agreement beyond chance between the 2 measurement methods.

Comparisons between patients with and without coronary artery disease: CLINICAL DATA (TABLE I): The clinical features of patients with MS are listed in Table I. Patients were significantly older and more frequently men in group 1 than in group 2 . Patients in group 1 had higher systolic arterial pressure, mean arterial pressure, and pulse pressure than those in group 2 (all $p<0.0001$ ). However, diastolic arterial pressure did not differ. There were no significant differences between the 2 groups in rhythm, heart rate, cigarette smoking, the frequency of hypertension, diabetes mellitus, hypercholesterolemia, or hypertriglycemia. 


\begin{tabular}{|c|c|c|}
\hline Parameters & $\begin{array}{l}\text { Group } 1 \\
\{n=48\rangle\end{array}$ & $\begin{array}{c}\text { Group } 2 \\
(n=111)\end{array}$ \\
\hline $\begin{array}{l}\text { LV end-diastolic dimension (mm) } \\
\text { LV end-systolic dimension (mm) } \\
\text { Interventricular septum thickness } \\
\text { (mm) }\end{array}$ & $\begin{array}{l}49 \pm 5 \\
34 \pm 5 \\
9.5 \pm 1.7\end{array}$ & $\begin{aligned} 47 & \pm 7 \\
32 & \pm 7 \\
7.9 & \pm 1.4^{*}\end{aligned}$ \\
\hline $\begin{array}{l}\text { LV posterior wall thickness }(\mathrm{mm}) \\
\text { LV ejection fraction }(\%) \\
\text { Mitral valve area }\left(\mathrm{cm}^{2}\right)\end{array}$ & $\begin{aligned} 9.7 & \pm 1.4 \\
65 & \pm 3\end{aligned}$ & $\begin{aligned} 8.2 & \pm 1.5^{\star} \\
65 & \pm 5\end{aligned}$ \\
\hline $\begin{array}{l}\text { Planimetry method } \\
\text { Doppler } \mathrm{t}_{1 / 2} \\
\text { Wall stress }\left(\text { dynes } / \mathrm{cm}^{2}\right) \\
\text { LV mass index }\left(\mathrm{g} / \mathrm{m}^{2}\right)\end{array}$ & $\begin{array}{l}0.86 \pm 0.18 \\
0.93 \pm 0.23 \\
108 \pm 39 \\
115 \pm 29\end{array}$ & $\begin{aligned} 0.85 & \pm 0.21 \\
0.95 & \pm 0.25 \\
107 & \pm 36 \\
90 & \pm 16^{*}\end{aligned}$ \\
\hline $\begin{array}{l}{ }^{*} p<0.0001 \\
\text { Values are expressed as mean } \pm S D \\
L V=\text { left ventricular; } t_{1 / 2}=\text { half-time }\end{array}$ & & \\
\hline
\end{tabular}

ECHOCARDIOGRAPHIC DATA (TABLE II): There was significantly higher echocardiographic interventricular septum thickness, left ventricular posterior wall thickness, and left ventricular mass index in group 1 patients (all $\mathrm{p}<0.0001$ ). No significant differences between the 2 groups were noted in left ventricular ejection fraction, end-systolic wall stress, and mitral valve areas, irrespective of planimetry or pressure half-time methods.

INVASIVE HEMODYNAMICS (TABLE III): Invasive (catheterization) and noninvasive (sphygmomanometer) systolic blood pressures were $154 \pm 14$ and $145 \pm$ $14 \mathrm{~mm} \mathrm{Hg}(\mathrm{p}=0.001)$ in group 1 , and $124 \pm 16$ and $119 \pm 11 \mathrm{~mm} \mathrm{Hg}(\mathrm{p}=0.008)$ in group 2 , respectively. Invasive and noninvasive diastolic blood pressures in the 2 groups were not significantly different. Pulse pressure had changed from $71 \pm 11 \mathrm{~mm} \mathrm{Hg}$ by the sphygmomanometer method to $81 \pm 15 \mathrm{~mm} \mathrm{Hg}$ by the catheterization method in group $1(p<0.0001)$, and from $48 \pm 12 \mathrm{~mm} \mathrm{Hg}$ by the sphygmomanometer method to $51+16 \mathrm{~mm} \mathrm{Hg}$ by the catheterization method in group $2(p=N S)$, respectively. There were no significant differences between the 2 groups in cardiac index, stroke index, and total peripheral resistance. Most of coronary lesions were in 1 or 2 vessels.

MULTIVARIATE LOGISTIC REGRESSION ANALYSIS: Although univariate analysis showed that older age, male sex, higher systolic blood pressure, higher mean blood pressure, higher pulse pressure assessed by sphygmomanometry, higher thickness of interventricular and left ventricular posterior wall, and higher left ventricular mass index were found to be significantly related to occurrence of CAD, we found that the best predicted covariates were age (standardized coefficient $\beta=1.3437, p=0.0025)$, gender $(\beta=0.0107$, $\mathrm{p}=0.0105)$, mean blood pressure $(\beta=1.1839, \mathrm{p}=$ $0.0105)$, and pulse pressure $(\beta=1.3157, \mathrm{p}=0.0008)$ by logistic regression nested model comparison.

Comparison between patients with a normal pulse pressure and a wide pulse pressure: PATIENTS' FEATURES (TABLE IV): There was a high percentage of older patients and men in a group with a wide pulse pressure compared with patients with a normal pulse pressure.
TABLE III Invasive Catheterization Hemodynamics in Patients With (group 1) and Without (group 2) Coronary Artery Disease

\begin{tabular}{|c|c|c|}
\hline Parameters & $\begin{array}{l}\text { Group } 1 \\
(n=48)\end{array}$ & $\begin{array}{l}\text { Group } 2 \\
(n=111)\end{array}$ \\
\hline Heart rate (beats/min) & $79 \pm 17$ & $73 \pm 17$ \\
\hline $\begin{array}{l}\text { Systolic arterial pressure } \\
\qquad(\mathrm{mm} \mathrm{Hg})\end{array}$ & $154 \pm 14$ & $124 \pm 16^{*}$ \\
\hline $\begin{array}{l}\text { Diastolic arterial pressure } \\
\qquad(\mathrm{mm} \mathrm{Hg})\end{array}$ & $73 \pm 17$ & $72 \pm 17$ \\
\hline $\begin{array}{l}\text { Mean arterial pressure (mm } \\
\mathrm{Hg})\end{array}$ & $100 \pm 16$ & $90 \pm 15^{\star}$ \\
\hline Pulse pressure $(\mathrm{mm} \mathrm{Hg})$ & $81 \pm 15$ & $51 \pm 16^{\star}$ \\
\hline Cardiac index $\left(\mathrm{ml} / \mathrm{min} / \mathrm{m}^{2}\right)$ & $2,420 \pm 390$ & $2,220 \pm 276$ \\
\hline Stroke index $\left(\mathrm{ml} / \mathrm{m}^{2}\right)$ & $31.2 \pm 6.3$ & $30.5 \pm 4.2$ \\
\hline $\begin{array}{l}\text { Total peripheral resistance } \\
\left(\text { dynes } \cdot \mathrm{s} \cdot \mathrm{cm}^{-5}\right)\end{array}$ & $2,077 \pm 445$ & $2,121 \pm 426$ \\
\hline \multicolumn{3}{|l|}{$\begin{array}{l}\text { Number of coronary } \\
\text { arterial narrowing } \geq 50 \%\end{array}$} \\
\hline 1 & $20(42 \%)$ & 0 \\
\hline 2 & $19(40 \%)$ & 0 \\
\hline 3 & $7(15 \%)$ & 0 \\
\hline 4 & $2(4 \%)$ & 0 \\
\hline
\end{tabular}

Left ventricular mass index was significantly higher in patients with a wide pulse pressure than in patients with a normal pulse pressure. Patients with a wide pulse pressure had an incidence of CAD of $59 \%(40$ subjects) compared with $8 \%$ (8 subjects) of patients with a normal pulse pressure $(\mathrm{p}<0.0001)$. There was no apparent relation of pulse pressure to echocardiographic end-systolic wall stress, stroke index, and peripheral resistance.

PULSE PRESSURE LEVELS AND CORONARY ATHEROSCLEROSIS (FIGURE 1): The frequency distribution of pulse pressures in groups with and without CAD is shown in Figure 1. Forty-eight of 159 patients with MS (30\%) had angiographically significant CAD. Of these 48 with $\mathrm{CAD}, 42(87.5 \%)$ had a pulse pressure $\geq 60 \mathrm{~mm} \mathrm{Hg}$. A wide pulse pressure $\geq 60 \mathrm{~mm} \mathrm{Hg}$ correlated with the presence of angiographically significant CAD with a sensitivity and specificity of $88 \%$ and $77 \%$. The positive accuracy of having significant $\mathrm{CAD}$ in the presence of a wide pulse pressure was $62 \%$. The negative predictive value was $93 \%$.

\section{DISCUSSION}

The principal finding of this study is that a wide pulse pressure is a simple clinical marker of CAD in paticnts with MS. Patients with a wide pulse pressure included a higher percentage of older patients, men, left ventricular mass index, and CAD.

Methodology: Interpretation of our current results should take into account 2 methodologic considerations. First, because data analysis in the present study was based on the differences of pulse pressures in a peripheral artery (brachial artery), it was important to show that pulse pressures could be reliably measured. The validity of the grouping and cutoff point of clinical pulse pressures was confirmed by invasive tech- 


\begin{tabular}{|c|c|c|c|}
\hline \multicolumn{4}{|c|}{$\begin{array}{l}\text { TABLE IV Clinical Parameters, Echocardiographic } \\
\text { Characteristics, and Invasive Hemodynamics in Patients } \\
\text { Grouped by Pulse Pressure }\end{array}$} \\
\hline & $\begin{array}{l}\text { Pulse Pressure } \\
<60 \mathrm{~mm} \mathrm{Hg} \\
(\mathrm{n}=91)\end{array}$ & $\begin{array}{l}\text { Pulse Pressure } \\
\geq 60 \mathrm{~mm} \mathrm{Hg} \\
(n=68)\end{array}$ & $p$ Value \\
\hline \multicolumn{4}{|l|}{ Clinical parameters } \\
\hline Age (yr) & $54 \pm 6$ & $57 \pm 9$ & 0.008 \\
\hline Men/women & $22 / 69$ & $35 / 33$ & $<0.0001$ \\
\hline Atrial fibrillation & 24 & 15 & NS \\
\hline Heart rate (beats/min) & $80 \pm 22$ & $80 \pm 19$ & NS \\
\hline $\begin{array}{l}\text { Systolic arterial } \\
\text { pressure }(\mathrm{mm} \mathrm{Hg})\end{array}$ & $118 \pm 11$ & $139 \pm 16$ & $>0.0001$ \\
\hline $\begin{array}{l}\text { Diastolic arterial } \\
\text { pressure }(\mathrm{mm} \mathrm{Hg})\end{array}$ & $74 \pm 12$ & $68 \pm 12$ & 0.004 \\
\hline $\begin{array}{l}\text { Mean arterial pressure } \\
(\mathrm{mm} \mathrm{Hg})\end{array}$ & $88 \pm 11$ & $92 \pm 13$ & NS \\
\hline $\begin{array}{l}\text { Pulse pressure }\{\mathrm{mm} \mathrm{Hg} \text { ) } \\
\text { Echocardiography }\end{array}$ & $44 \pm 8$ & $71 \pm 8$ & $<0.0001$ \\
\hline LV ejection fraction (\%) & $65 \pm 6$ & $66 \pm 4$ & NS \\
\hline Wall stress $\left(\right.$ dynes $\left./ \mathrm{cm}^{2}\right)$ & $110 \pm 36$ & $105+37$ & NS \\
\hline LV mass index $\left(\mathrm{g} / \mathrm{m}^{2}\right)$ & $86 \pm 23$ & $98 \pm 25$ & 0.003 \\
\hline \multicolumn{4}{|l|}{ Catheterization } \\
\hline $\begin{array}{l}\text { Cardiac index }(\mathrm{m} / / \\
\left.\mathrm{min} / \mathrm{m}^{2}\right)\end{array}$ & $2,295 \pm 295$ & $2,260 \pm 331$ & NS \\
\hline Stroke index $\left(\mathrm{ml} / \mathrm{m}^{2}\right)$ & $30 \pm 4$ & $31 \pm 6$ & NS \\
\hline $\begin{array}{l}\text { Total peripheral } \\
\text { resistance (dynes. } \\
\mathrm{s} \cdot \mathrm{cm}^{-5} \mid\end{array}$ & $2,090 \pm 429$ & $2,130 \pm 437$ & NS \\
\hline $\begin{array}{l}\text { Coronary artery } \\
\text { disease }\end{array}$ & $8(8 \%)$ & $40(59 \%)$ & $<0.0001$ \\
\hline
\end{tabular}

nique as was the observation of Safar et al. ${ }^{12}$ It is not practical to invasively monitor pressure in the proximal aorta in a clinical setting. It is desirable to know the differences of pulse pressures between central and peripheral arteries. There were curious differences between central and peripheral pressures that are likely to be attributable to wave reflection. Karamanoglu et al ${ }^{13}$ demonstrated that ascending aortic pulse pressure is less than that in the brachial artery, contrary to our results. This may be explained in part by different measurement methods. Karamanoglu used high-fidelity Millar catheters to measure both central and peripheral blood pressure. In our study, 1 measurement (peripheral brachial artery) was by means of noninvasive sphygmomanometer, while the other (the aorta) was by use of an invasive catheterization technique that seems to be influenced by emotion. Sympathetic activation would result in an increased pulse pressure. ${ }^{14}$ Atrial fibrillation was present in 120 of the 159 patients. This would be expected to affect the accuracy of blood pressure measurements. We averaged 3 measurements for systolic and diastolic pressures, which would minimize the variation. ${ }^{4}$ The case number of atrial fibrillation in the 2 groups with normal and wide pulse pressures did not show a significant difference. Thus, atrial fibrillation is unlikely to have affected the results. The other main criticism is to estimate coronary diameter stenosis visually, which is a potential variable associated with operator dependence. $^{15}$ The overall $\kappa$ of 0.93 for the grading of

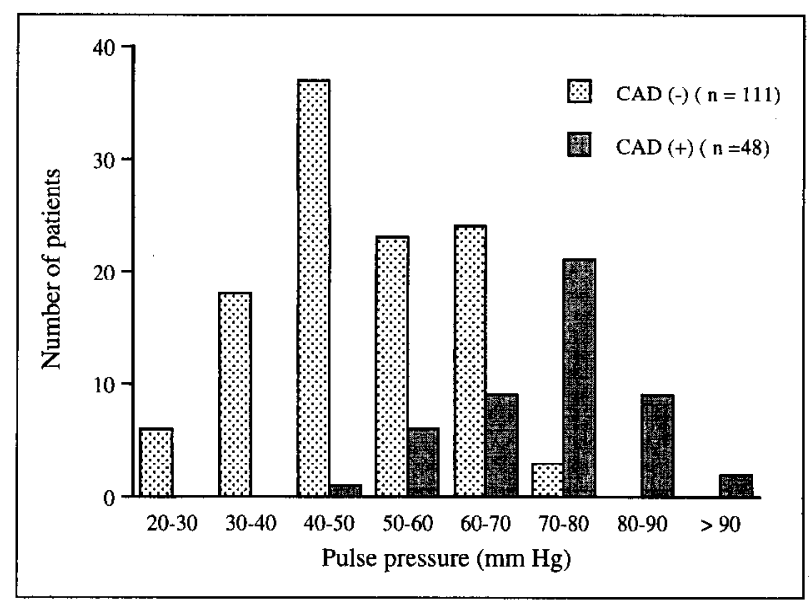

FIGURE 1. The frequency distribution of pulse pressures in the groups with $(+)$ and without $(-)$ coronary artery disease (CAD).

coronary artery lesions allows a reliable grading of $<50 \%$ or $\geq 50 \%$.

Pulse pressure and coronary artery disease: In multivariate models, although the contribution of other factors was profound, pulse pressure was an independent predictor of the development of CAD. The mechanisms underlying the association between pulse pressures and CAD are unclear.

Pulse pressure and left ventricular mass: Our results confirmed the observation of Darne et al ${ }^{16}$ that pulse pressure was independently associated with left ventricular hypertrophy. The medial hyperplasia of small resistance arteries was closely correlated with the magnitude of pulse pressure. Increased peripheral resistance associated with medial hyperplasia of small resistance arteries may be responsible for left ventricular hypertrophy in patients with a wide pulse pressure. The present study, however, demonstrated that ventricular end-systolic wall stress and peripheral resistance were similar in patients with normal and wide pulse pressures, suggesting that other factors are responsible for ventricular hypertrophy. London et al ${ }^{17}$ showed that the degree of ventricular hypertrophy is influenced not only by peripheral resistance, but also by the reduction of arterial compliance and the timing and intensity of wave reflections.

Acknowledgment: We acknowledge the helpful comments of Krishnankutty Sudhir, MD, PhD (University of California, San Francisco) and the statistical assistance and advice of Yuh-Chen Huang.

1. Mattina CJ, Green SJ, Tortolani AJ, et al. Frequency of angiographically significant coronary arterial narrowing in mitral stenosis. Am J Cardiol 1986;57 $802-805$.

2. Tadavarthy SM, Vlodaver Z, Edwards JE. Coronary atherosclerosis in subjects with mitral stenosis. Circulation 1976;54:519-521.

3. Lyon RT, Runyon-Hass A, Davis HR, Glagov S, Zarins CK. Protection from atherosclerotic lesion formation by reduction of artery wall motion. I Vasc Surg 1987;5:59-67.

4. Kirdendall WM, Feinleib MH, Freis ED, Mark AL. Recommendation for human blood pressure determination by sphygmomanometers. Hypertension 1981:3:509A-519A.

5. Teichholz LE, Kreulen T, Herman MV, Gorlin R. Problems in echocardio- 
graphic volume determinations: echocardiographic-angiographic correlations in the presence or absence of asynergy. Am J Cardiol 1976;37:7-11.

6. Devereux RB, Alonso DR, Lutas EM, et al. Echocardiographic assessment of left ventricular hypertrophy: comparison to necropsy findings. Am J Cardiol 1986;57:450-458.

7. Grossman W, Jones D, McLaurin LP. Wall stresses and patterns of hypertrophy in the human left ventricle. $J$ Clin Invest 1975;56:56-64.

8. Hatle L, Angelsen B, Tromsdal A. Noninvasive assessment of atrioventricular pressure half-time by Doppler ultrasound. Circulation 1979;60:1096-1104.

9. Lee TM, Su SF, Chen MF, Liau CS, Lee YT. Effects of increasing flow rate on aortic indices: evidence from percutaneous balloon dilation of the valve in patients with combined aortic and mitral stenosis. Heart 1996;76: $490-494$.

10. Lee TM, Chu CC, Hsu YM, Chen MF, Liau CS, Lee YT. Exaggerated luminal loss a few minutes after successful percutaneous transluminal coronary angioplasty in patients with recent myocardial infarction compared with stable angina: an intracoronary ultrasound study. Cathet Cardiovasc Diagn 1997;41:32-39.

11. Kraemer HL, Bloch DA. Kappa coefficients in epidemiology: an appraisal of a reappraisal. J Clin Epidemiol 1988:41:959-968.

12. Safar ME, St Laurent S, Safavian AL, Pannier BM, London GM. Pulse pressure in sustained essential hypertension: a haemodynamic study. $J$ Hypertens $1987 ; 5: 213-218$.

13. Karamanoglu M, O'Rourke MF, Avolio AP, Kelly RP. An analysis of the relationship between central aortic and peripheral upper limb pressure waves in man. Eur Heart $J$ 1993;14:16-17.

14. Boutouyrie P, Lacolley P, Girerd X, Beck L, Safar M, Laurent S. Sympathetic activation decreases medium-sized arterial compliance in humans. Am J Physiol 1994;267 (Heart Circ Physiol 36):H1368-H1376.

15. Klein JL, Boccuzzi SJ, Treasure CB, Manoukian SV, Vogel RA, Beauman GJ, Fischman D, Savage MP, Weintraub WS, for the Lovastatin Restenosis Trial Group. Performance standards and edge detection with computerized quantitative coronary arteriography. Am J Cardiol 1996;77:815-822.

16. Darne B, Girerd X, Safar M, Cambien F, Guise L. Pulsatile versus steady component of blood pressure: a cross-sectional analysis and a prospective analysis on cardiovascular mortality. Hypertension 1989;13:392-400.

17. London GM, Pannier B, Guerin AP, Marchais SJ, Safar ME, Cuche JL. Cardiac hypertrophy, aortic compliance, peripheral resistance, and wave reflection in end-stage renal disease: comparative effects of ACE inhibition and calcium channel blockade. Circulation 1994;90:2786-2796. 